\title{
Rancang Bangun Sistem Kendali Kecepatan Motor Induksi 1 Fasa Dengan Pengaturan Sudut Penyalaan (Firing Angle) Triac pada Konveyor Model Rotary Pengering Karet
}

\author{
Anizar Indriani, Faisal Hadi, Rahmat Aulani \\ Program Studi Teknik Elektro Fakultas Teknik Universitas Bengkulu \\ *E-mail: aniz_raimin@yahoo.com
}

\begin{abstract}
Induction motor speed control system is a system that regulates the speed of an induction motor as a drive that works automatically. The use of induction motors is often needed to operate at varying speeds as used in the production process in a factory as a conveyor drive. The one phase induction motor speed control system as a conveyor drive for the rotary dryer model uses a Proportional Integral Derivative (PID) based microcontroller with the TRIAC firing angle setting. This control system is used to get a constant speed despite changes in load. The controller provides feedback on the AC Dimmer Zero Detector to produce the appropriate duty cycle to reach the setpoint speed. In the no-load test the biggest rise time value is $\mathbf{5 . 2 9}$ seconds when the setpoint speed is $42 \mathrm{rpm}$. In load testing with a load variation of 1000 grams, the motor's largest steady state time value is 6.23 seconds. Power consumption of induction motor when using a speed control system for no load at $36 \mathrm{rpm}$ is 16.52 Watt. In testing with the load at $36 \mathrm{rpm}$ is $\mathbf{1 8 . 3 6}$ Watts. Key word : speed, induction motor, rotary dryer, firing angle control.
\end{abstract}

\section{ABSTRAK}

Sistem kendali kecepatan motor induksi merupakan sistem yang mengatur kecepatan motor induksi sebagai penggerak yang bekerja secara otomatis. Penggunaan motor induksi sering dibutuhkan untuk beroperasi pada kecepatan yang bervariasi seperti digunakan pada proses produksi di suatu pabrik sebagai penggerak konveyor. Sistem pengendalian kecepatan motor induksi satu fasa sebagai penggerak konveyor model rotary pengering karet menggunakan mikrokontroller berbasis Proportional Integral Derivative (PID) dengan pengaturan sudut penyalaan (firing angle) TRIAC. Sistem kendali ini digunakan untuk mendapatkan kecepatan konstan meskipun terjadi perubahan beban. Pengendali memberikan umpan balik pada AC Dimmer Zero Detector agar menghasilkan duty cycle yang sesuai guna mencapai kecepatan setpoint. Pada pengujian tanpa beban diperoleh nilai rise time terbesar yaitu 5.29 sekon pada saat kecepatan setpoint sebesar $42 \mathrm{rpm}$. Pada pengujian berbeban dengan variasi beban 1000 gram, didapatkan nilai steady state time terbesar motor yaitu 6.23 sekon. Konsumsi daya motor induksi saat menggunakan sistem pengendali kecepatan, pada pengujian tanpa beban di kecepatan $36 \mathrm{rpm}$ sebesar 16.52 Watt. Pada pengujian berbeban pada kecepatan $36 \mathrm{rpm}$ yaitu 18.36 Watt.

Kata Kunci: kecepatan, motor induksi, pengering berputar, pengaturan sudut penyalaan.

\section{PENDAHULUAN}

Pada pabrik pengolahan karet, proses pengeringan karet masih dilakukan secara alami dengan panas matahari. Sistem pemindahan karet yang akan dikeringkan dilakukan secara manual oleh banyak pekerja, seperti untuk memindahkan karet ke tempat pengeringan dan menyusun karet untuk proses pengeringan. Hal ini tentunya membuat suatu pekerjaan menjadi tidak efisien dan membutuhkan waktu serta tenaga yang banyak yang membuat biaya produksi menjadi lebih tinggi.

Untuk mengatasi masalah-masalah tersebut maka diaplikasikanlah sistem kendali berbasis Arduino sebagai pengendali konveyor yang digerakkan oleh motor induksi 1 fasa pada alat pengering karet dengan pengaturan sudut penyalaan (firing angle) TRIAC untuk mempermudah dan mempercepat waktu proses pengeringan karet sehingga dapat menekan biaya produksi dan menghemat konsumsi daya listrik yang digunakan pada produksi pengeringan karet. Oleh karena itu, diaturlah kecepatan motor agar tetap stabil dan mempertahankan kecepatannya seiring dengan adanya penambahan beban berupa karet sesuai dengan instruksi yang telah ditentukan pada input Arduino berupa sensor atau switch.

\section{KERANGKA TEORITIS DAN PENGEMBANGAN HIPOTESIS}

\subsection{Motor Induksi}

Motor induksi juga disebut mesin asinkron (mesin tak serempak), hal ini dikarenakan putaran motor tidak sama dengan putaran fluks magnet stator. Dengan kata lain, bahwa antara rotor dan fluks magnet stator terdapat selisih perputaran yang disebut dengan slip. Pada umumya 


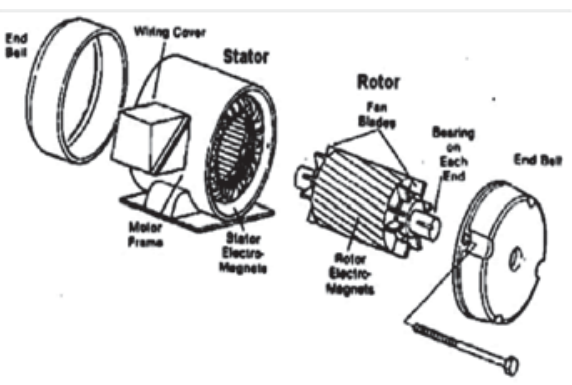

Gambar 1. Konstruksi Motor Induksi[1]

motor dengan supply tegangan AC yang digunakan adalah motor induksi, terutama motor induksi satu fasa yang paling banyak dipakai di perindustrian. Motor induksi satu fasa sangat banyak dipakai sebagai penggerak di perindustrian karena banyak memiliki keuntungan, tetapi juga memiliki beberapa kelemahan. Jika arus lewat pada suatu konduktor, timbul medan magnet di sekitar konduktor. Arah medan magnet ditentukan oleh arah aliran arus pada konduktor. Motor induksi merupakan motor listrik arus bolak balik (AC) yang paling luas digunakan, karena konstruksinya yang kuat dan karakteristik kerjanya yang baik. Secara umum motor induksi terdiri dari rotor dan stator. Rotor merupakan bagian yang bergerak, sedangkan stator bagian yang diam. Diantara stator dengan rotor ada celah udara yang jaraknya sangat kecil. Konstruksi motor induksi dapat dilihat pada Gambar 1 .

Jika pada belitan stator diberi tegangan satu fasa, maka pada stator akan dihasilkan arus, arus ini menghasilkan medan magnetik yang berputar dengan kecepatan sinkron. Ketika medan melewati konduktor rotor, dalam konduktor ini diinduksikan ggl yang sama seperti ggl yang diinduksikan dalam belitan sekunder transformator oleh fluks arus primer. Rangkaian rotor merupakan rangkaian tertutup, baik melalui cincin ujung atau tahanan luar, ggl induksi menyebabkan arus mengalir dalam konduktor rotor. Jadi arus yang mengalir pada konduktor rotor dalam medan magnet yang dihasilkan stator akan menghasilkan gaya (F) yang bekerja pada rotor. Apabila belitan stator diberi tegangan dari sumber tegangan satu fasa, maka akan timbul medan magnet yang berputar dengan kecepatan sinkron [1]:

$$
N s=\frac{120 \quad f}{p}
$$

(1)

$$
\begin{aligned}
& \text { dengan : } \\
& \begin{array}{l}
\mathrm{Ns}=\text { Kecepatan medan putar stator }(\mathrm{rpm}) \\
\mathrm{F}=\text { Frekuensi jaringan }(\mathrm{Hz}) \\
\mathrm{P}=\text { Jumlah kutub }
\end{array}
\end{aligned}
$$

Medan putar tersebut akan memotong konduktor rotor hingga terbangkitlah tegangan induksi. Karena konduktor rotor dihubung singkat, maka akan mengalir arus dalam konduktor rotor. Arus rotor ini berada dalam medan magnet dari stator menurut hukum Lorenz akibatnya timbul gaya/torka. Bila gaya ini cukup untuk menggerakkan rotor maka ia akan berputar dengan kecepatan [1]:

$$
\begin{aligned}
& m_{r}=(1-S) m_{s} \\
& \text { dengan: } \\
& \mathrm{mr}=\text { Kecepatan sudut rotor }(\mathrm{rad} / \mathrm{s}) \\
& \mathrm{S}=\text { Slip putaran }
\end{aligned}
$$

Tegangan induksi hanya akan terbangkitkan jika terjadi perpotongan antar medan putar dengan konduktor rotor maka kecepatan rotor tidak dapat menyamai kecepatan medan putar stator. Harus ada selisih dimana kecepatan rotor (nr) harus lebih rendah dari kecepatan medan putar (kecepatan sinkron ns). Perbedaan kecepatan ini disebut slip (S) dan dinyatakan dengan [9]:

$$
\begin{array}{cl}
S=\frac{N_{s}-N_{r}}{N_{s}} & \\
\text { dengan: } & \\
\mathrm{S} & =\text { Slip } \\
\mathrm{Ns} & =\text { Kecepatan Sinkron } \\
\mathrm{Nr} & =\text { Kecepatan Rotor }
\end{array}
$$

Adanya perbedaan kecepatan medan putar dan rotor ini sehingga mesinnya disebut mesin tak sinkron/serempak [1].

\subsection{Zero Crossing Detector}

Zero crossing detector merupakan rangkaian elektronika yang berfungsi untuk mendeteksi titik persilangan nol pada suatu sinyal ac baik sinus maupun

sinyal ac lainnya. Rangkaian zero crossing detector sering diaplikasikan pada peralatan yang digunakan untuk mengendalikan beban pada jaringan listrik AC dan menggunakan eksekutor berupa TRIAC atau SCR. Titik persilangan dengan nol tegangan sumber untuk beban yang dikendalikan dengan komponen saklar berupa TRIAC atau SCR diperlukan untuk menentukan waktu mulai pemberian trigger atau sinyal kontrol pada SCR atau TRIAC tersebut. Pemberian sinyal input pada SCR atau TRIAC yang tepat pada titik persilangan nol akan meningkatkan efektifitas adan efisiensi daya output dari pengendalian beban listrik AC[2]. 


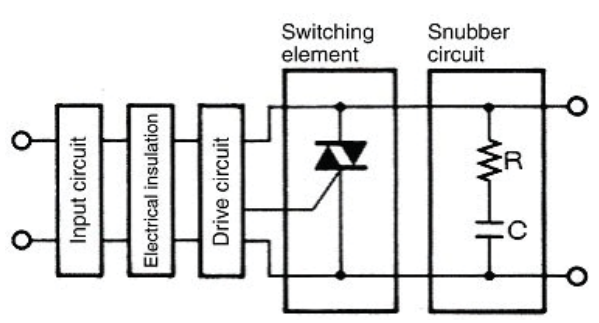

Gambar 2. Sinyal Output Zero Crossing Detector Circuit dan SSR Beban Resistif [2].

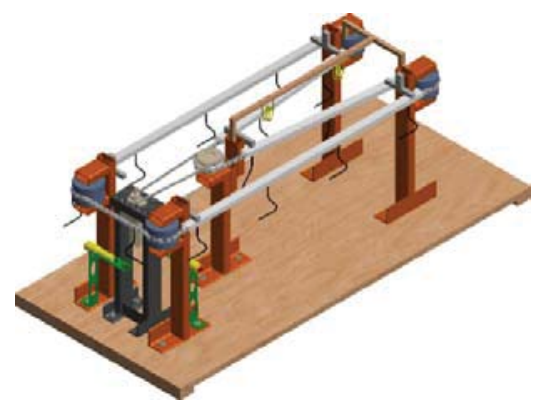

Gambar 3. Perancangan Prototipe Alat Pengering Karet

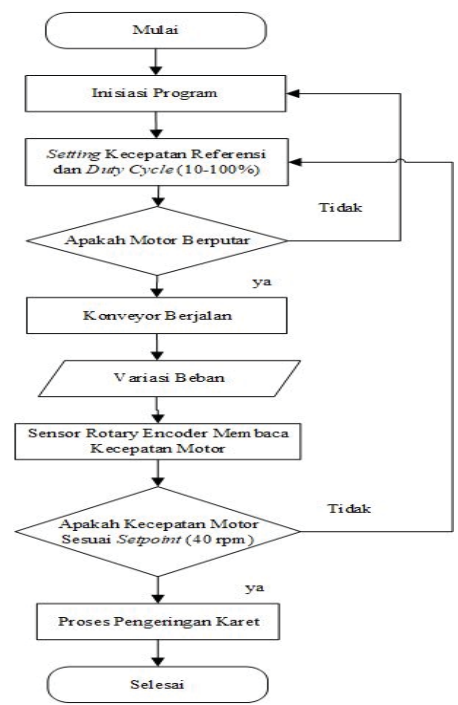

Gambar 4. Diagram Alir Sistem

Output dari opto- isolator akan mengendalikan TRIAC yang dihubungkan secara seri dengan beban pada tiap fasa. Optoisolator ini hanya akan beroperasi pada posisi zero voltage crossing bahkan jika switching berada pada tegangan puncak, beban akan kembali $O N$ setelah melewati zero voltage crossing. Dari penerapan ZVS tersebut akan menghasilkan efisiensi yang lebih baik saat proses switching. ZVS akan meningkatkan umur pemakaian dari kontroler serta beban dan mengurangi kemungkinan pembentukan busur di relai. Tanpa ZVC, optoisolator dapat beroperasi, namun pada tegangan yang kuat dapat mengakibatkan busur api (spark).

\section{METODE RISET}

\subsection{Perancangan Prototipe Alat Pengering Karet}

Secara umum sistem yang dirancang dapat dibagi ke dalam dua buah bagian yaitu hardware dan juga software. Sistem hardware terdiri atas prototipe alat pengering karet, mikrokontroler Arduino, rangkaian AC Dimmer. Sistem software terdiri atas program pada mikrokontroler Arduino. Adapun rancangan prototipe alat dapat dilihat pada Gambar 3.

Konstruksi prototipe alat dirancang berbentuk kotak dengan tinggi $22 \mathrm{~cm}$ dan lebar $47 \mathrm{~cm}$.Pada prototipe terdapat motor induksi 1 fasa, sensor kecepatan, konveyor dan hanger yang berfungsi sebagai pembawa karet-karet yang akan dikeringkan. Sedangkan rangkaian kontrol terdapat di bagian bawah, terpisah dengan prototipe alat. Tampilan hasil pendeteksi kecepatan akan ditampilkan pada LCD yang terdapat dibagian kontrol. Pada penelitian ini instruksi dilakukan sesuai dengan tahapan pada diagram alir sistem kendali kecepatan motorseperti yang ditunjukkan pada Gambar 4

Berdasarkan Gambar 4 diagram alir sistem kendali kecepatan motor dapat dijelaskan sebagai berikut: 1.Pada tahap pertama menginisiasi program, pada tahap ini menjelaskan fungsi dari masing-masing program yang telah diinputkan.

2.Setting kecepatan referensi dan duty cycle yang diproses menggunakan mikrokontroller Arduino Uno.

3.Selanjutnya dilakukan interupsi, apakah motor telah berputar. Apabila motor berputar maka akan mengakibatkan konveyor berjalan untuk proses pengeringan karet sehingga proses pengeringan dapat dijalankan. Apabila motor induksi belum berputar, maka akan kembali ke proses sebelumnya yaitu inisiasi program 4. Jika konveyor telah berjalan, maka proses selanjutnya ialah pemberian variasi beban dengan menggantungkan karet-karet pada konveyor untuk dilakukan proses pengeringan menuju heater dan blower.

5. Selanjutnya Sensor Rotary Encoder akan membaca kecepatan putaran motor ketika variasi beban diberikan. Jika kecepatan stabil maka proses tersebut akan terus berlangsung, namun jika kecepatan putaran motor menurun, maka sensor akan memberikan feedback ke Arduino.

6. Kemudian dilakukan interupsi apakah kecepatan putaran motor sesuai dengan setpoint (40 rpm). Jika kecepatan putaran motor sesuai dengan setpoint yang ditentukan, maka proses pengeringan akan berlanjut. Namun jika kecepatan putaran motor tidak sesuai dengan 
Tabel 1. Pengujian Rise Time Tanpa Beban

\begin{tabular}{ccccccc}
\hline \multirow{2}{*}{$\begin{array}{c}\text { Kecepatan } \\
\text { Referensi } \\
(\mathrm{RPM})\end{array}$} & $\begin{array}{c}\text { Frekuensi } \\
(\mathrm{Hz})\end{array}$ & $\begin{array}{c}\text { Tegangan } \\
(\mathrm{V})\end{array}$ & $\begin{array}{c}\text { Arus } \\
(\mathrm{A})\end{array}$ & $\begin{array}{c}\text { Rise } \\
\text { Time } \\
\text { (s) }\end{array}$ \\
\cline { 3 - 7 } & & & & & & \\
& & $\mathrm{V}_{\text {in }}$ & $\mathrm{V}_{\text {out }}$ & $\mathrm{I}_{\text {in }}$ & $\mathrm{I}_{\text {out }}$ & \\
\hline 42 & 50 & 230 & 228 & 0.10 & 0.09 & 5.29 \\
\hline 40 & 50 & 228 & 226 & 0.10 & 0.09 & 4.63 \\
\hline 38 & 50 & 225 & 223 & 0.09 & 0.08 & 4.44 \\
\hline 36 & 50 & 220 & 219 & 0.08 & 0.07 & 3.48 \\
\hline
\end{tabular}

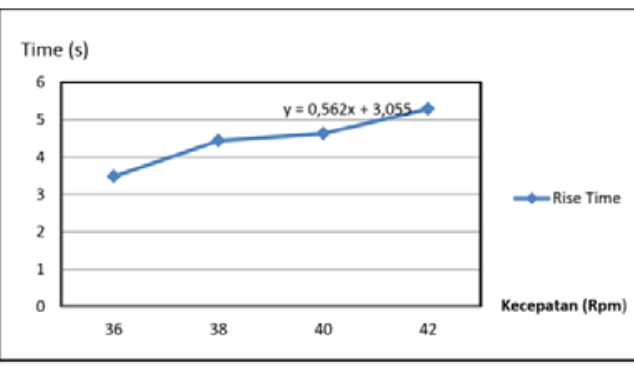

Gambar 4. Grafik Perbandingan Rise Time Pada Kecepatan Referensi yang Berbeda

setpoint, maka Arduino akan mengatur nilai duty cycle yang tepat untuk menaikkan kecepatan putaran motor sehingga mencapai nilai setpoint yang telah ditentukan.

\section{HASIL DAN PEMBAHASAN 4.1Pengujian Pengujian Karakteristik Motor Induksi 1 Fasa Tanpa Beban. \\ 4.1.1 Pengujian Rise Time Motor Tanpa Beban}

Pengujian pertama adalah pengujian rise time motor tanpa beban. Pengujian ini dilakukan untuk melihat seberapa cepat motor mencapai kecepatan referensi dalam keadaan tanpa beban. Respon motor untuk mencapai kecepatan referensi dikendalikan oleh mikrokontroller melalui PID dengan pengujian berulang-ulang (trial error). Pada pengujian ini, kecepatan referensi yang diberikan bervariasi mulai dari $36 \mathrm{rpm}$ sampai dengan $42 \mathrm{rpm}$. Pengujian dilakukan sebanyak 4 kali dengan kecepatan referensi yang berbeda dengan menggunakan timer. Hasil pengujian dapat dilihat pada Tabel 1.

Berdasarkan Tabel 1 terlihat bahwa semakin besar nilai setpoint yang diberikan, maka semakin lama pula waktu yang dibutuhkan motor untuk mencapai kecepatan setpoint. Rise time motor untuk menuju keadaan kecepatan referensi juga semakin mengecil karena kecepatan referensi yang ditentukan semakin menurun. Hal ini dikarenakan, sistem pengendali akan mengatur kecepatan motor lebih cepat pada kecepatan referensi yang lebih kecil. Jika kecepatan referensi besar, maka

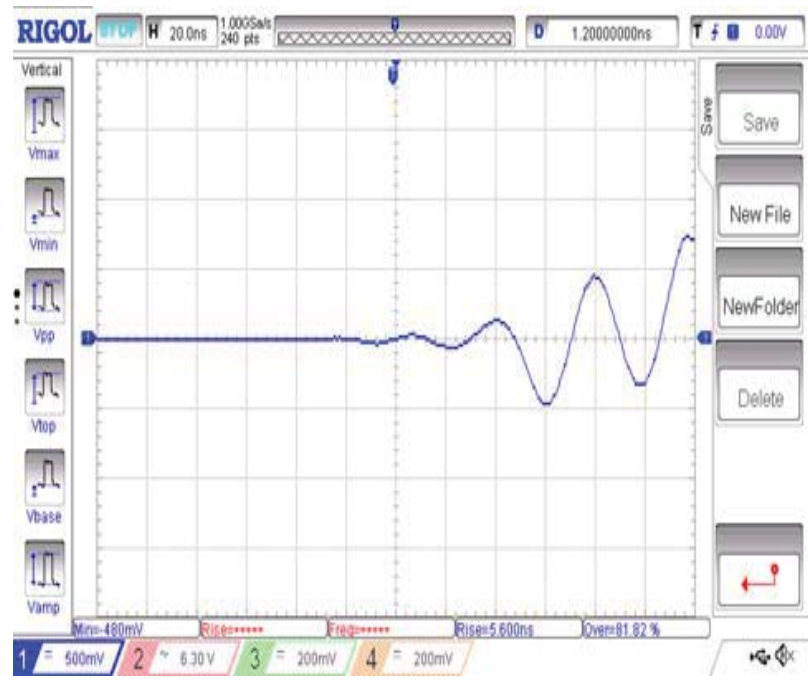

Gambar 5. Sinyal Kecepatan Motor Pada Kecepatan Setting 36 rpm Tanpa Beban

pengendali membutuhkan waktu yang lebih lama untuk menuju kecepatan tersebut.

Gambar 4. menunjukkan grafik perbandingan rise time motor dengan kecepatan referensi yang berbeda. Dari grafik di atas, didapatkan bahwa semakin besar kecepatan referensi yang ditentukan, maka semakin lama pula rise time motor yang dihasilkan. Sebaliknya semakin kecil kecepatan referensi, semakin cepat pula rise time motor tersebut. Hal ini dikarenakan sistem kendali memerlukan waktu tertentu untuk mengatur motor agar berada pada kecepatan referensinya.

Pengujian selanjutnya dilakukan dengan mengamati respon motor ketika berputar menggerakkan konveyor. Berbeda dengan pengujian sebelumya dengan menggunakan timer, pada pengujian ini digunakan osiloskop untuk melihat secara jelas sinyal kecepatan dari respon motor ketika berputar menuju kecepatan referensi yang telah ditentukan. Adapun sinyal kecepatan motor pada kecepatan setting $36 \mathrm{rpm}$ tanpa beban dapat dilihat pada Gambar 5.

\subsubsection{Pengamatan Sinyal Tegangan Output yang Dihasilkan Rangkaian AC Dimmer}

Metode pengendalian untuk membangkitkan magnitude tegangan pada penelitian ini menggunakan pengaturan sudut penyalaan TRIAC yang dibangkitkan dengan menggunakan Arduino sebagai kontroller. Pengamatan yang dilakukan meliputi pengamatan bentuk gelombang tegangan output rangkaian AC Dimmer. Sampel pengamatan dari pengujian yang dilakukan adalah pada range nilai dimming (10-100) dengan duty cycle yang didapatkan mulai dari 48\% hingga 93\% yang dapat dilihat berdasarkan hasil tampilan osiloskop seperti yang ditunjukan pada Gambar 5. 


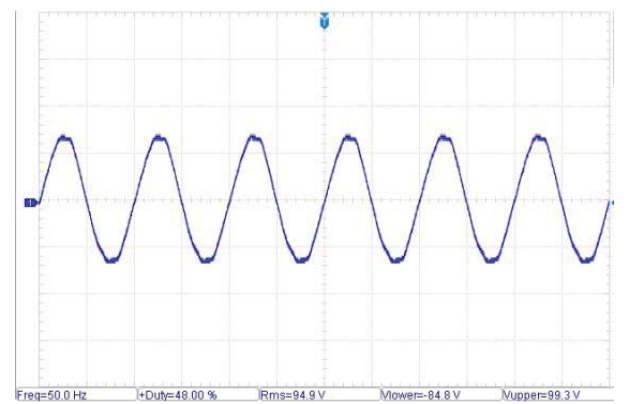

Gambar 6. Gelombang Output Driver TRIAC Dimming 10

Tabel 2 Pengujian Kestabilan Kecepatan Motor Induksi 1 Fasa dengan Kecepatan Setpoint 40 Rpm

\begin{tabular}{|c|c|c|c|c|c|c|c|c|}
\hline \multirow{3}{*}{$\begin{array}{c}\text { Beban } \\
\text { (gr) }\end{array}$} & \multirow{2}{*}{\multicolumn{2}{|c|}{ Tegangan $(\mathrm{V})$}} & \multirow{2}{*}{\multicolumn{2}{|c|}{$\begin{array}{l}\text { Arus } \\
\text { (A) }\end{array}$}} & \multirow{3}{*}{$\begin{array}{c}\text { Frekuensi } \\
(\mathrm{Hz})\end{array}$} & \multicolumn{3}{|c|}{ Kecepatan Motor Steady } \\
\hline & & & & & & & pm) & State \\
\hline & $\mathrm{V}_{\text {in }}$ & $V_{\text {out }}$ & $\mathrm{I}_{\text {in }}$ & $\mathrm{I}_{\text {out }}$ & & $\begin{array}{c}\text { Kec } \\
\text { Awal }\end{array}$ & $\begin{array}{c}\text { Kec } \\
\text { Akhir }\end{array}$ & $\begin{array}{l}\text { Time } \\
\text { (s) }\end{array}$ \\
\hline 300 & 209.2 & 207 & 0.10 & 0.09 & 50 & 38.9 & 41.2 & 4.58 \\
\hline 500 & 205.4 & 203.1 & 0.11 & 0.09 & 50 & 37 & 41.17 & 5.75 \\
\hline 700 & 203.3 & 198.9 & 0.11 & 0.10 & 50 & 34.3 & 40.5 & 6.01 \\
\hline 1000 & 198.7 & 191.9 & 0.12 & 0.11 & 50 & 30.5 & 40.2 & 6.23 \\
\hline
\end{tabular}

Pada Gambar 6 tampilan osiloskop, terlihat bahwa gelombang output yang terbentuk dengan nilai dimming 10 menghasilkan gelombang yang masih rapat dengan nilai duty cycle yang didapatkan sebesar $48 \%$ dan nilai frekuensi sebesar $50 \mathrm{~Hz}$. Nilai duty cycle yang didapatkan tersebut dipengaruhi oleh nilai dimming yang diberikan pada mikrokontroller Arduino dimana semakin besar nilai dimming yang diberikan, maka akan memperbesar nilai duty cycle dan magnitude tegangan yang dihasilkan. Pengujian selanjutnya yaitu dengan melihat tegangan keluaran yang dihasilkan gelombang output dari driver TRIAC yang disesuaikan dengan nilai duty cycle yang diberikan.

\subsection{Hasil Pengujian Karakteristik Kecepatan Motor Induksi 1 Fasa dengan Sistem Pengendali}

Pengujian ini dilakukan menggunakan sistem secara keseluruhan dengan dengan sistem pengendali untuk melihat kestabilan kecepatan motor ketika motor diberikan beban. Hal ini dilakukan untuk melihat pengaruh pemberian beban berupa karet pada konveyor terhadap kinerja dari sistem pengendali. Beban akan diberikan secara bertahap mulai dari 300 g, 500 g, 700 g dan 1000 g. Kemudian digunakan timer untuk melihat waktu yangdibutuhkan pengendali untuk mengembalikan kecepatan motor pada kecepatan setpoint. Kecepatan setpoint yang ditentukan sebesar 40 rpm karena dianggap sebagai kecepatan yang tepat bagi

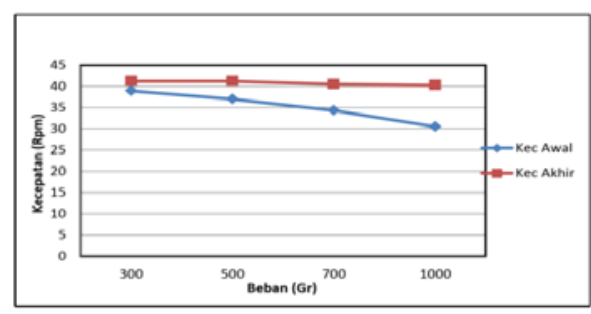

Gambar 7. Grafik Perbandingan Kecepatan Motor Induksi Pada Saat Pembebanan

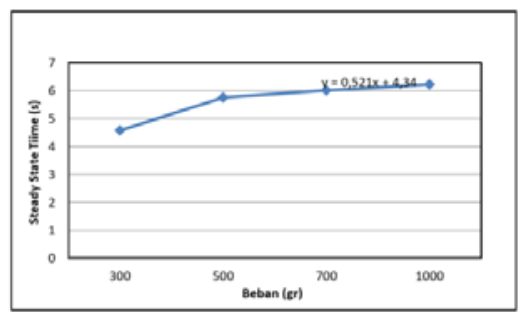

Gambar 7. Grafik Steady State Time Motor dengan Pembebanan

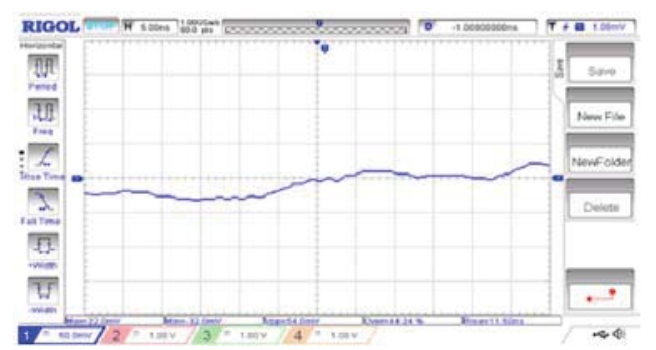

Gambar 8. Sinyal Kecepatan Motor Pada Beban 300 gr

konveyor untuk memindahkan beban. Adapun data hasil pengujian dapat dilihat pada Tabel 2 .

Berdasarkan Tabel 2 dapat dilihat perubahan kecepatan motor yang dihasilkan ketika konveyor diberikan beban berupa karet. Kecepatan yang didapat cenderung menurun seiring dengan besarnya beban yang diberikan. Begitupun waktu yang dibutuhkan untuk kembali menuju kecepatan setpoint yang semakin lama ketika beban yang diberikan semakin besar. Untuk melihat pegaruh pemberian beban terhadap kecepatan motor dan juga steady state time motor dapat dilihat pada Gambar 10.

Gambar 7 menunjukkan grafik perbandingan kecepatan motor pada saat pembebanan. Dari grafik di atas, dapat dilihat perbedaan antara nilai kecepatan awal motor ketika dibebani dengan kecepatan akhir motor pada saat sistem pengendali mulai bekerja untuk mengembalikan kecepatan motor ke nilai setpoint berupa $40 \mathrm{rpm}$. Pada saat beban 300 dan $500 \mathrm{~g}$, kecepatan motor menurun menjadi 38.9 dan $37 \mathrm{rpm}$. Kemudian, setelah sistem pengendali bekerja, kecepatan motor berubah menjadi 41.2 dan $41.17 \mathrm{rpm}$. 
Berdasarkan Gambar 7 dapat dilihat nilai steady state time motor terhadap masing-masing beban yang diberikan. Dari grafik di atas menunjukkan kenaikan nilai steady state time motor yang linier dengan penambahan beban yang diberikan. Pada saat beban sebesar $300 \mathrm{~g}$, waktu yang diperlukan pengendali untuk mengembalikan kecepatan motor menuju kecepatan setpoint (steady statetime) sebesar $4.58 \mathrm{~s}$. Artinya waktu yang dibutuhkan pengendali tidak lebih dari 5 detik.

Namun pada saat beban dinaikkan menjadi masing-masing 500, 700 dan 1000 g, nilai steady state time motor yang didapatkan semakin besar masingmasing yaitu sebesar 5.75, 6.01 dan 6.23 s. Sehingga dapat disimpulkan bahwa nilai steady state time motor akan semakin besar atau dengan kata lain, pengendali membutuhkan waktu yang sedikit lebih lama untuk mengembalikkan motor ke kecepatan setpoint ketika beban yang diberikan semakin besar.

Pengujian berikutnya dilakukan dengan menggunakan osiloskop untuk melihat respon motor terhadap pembebanan yang diberikan. Beban diberikan secara bertahap mulai dari 300 g, 500 g, 700 g dan 1000 g. Kecepatan setting yang ditentukan sebesar $40 \mathrm{rpm}$ karena dianggap sebagai kecepatan yang tepat bagi konveyor untuk memindahkan beban. Adapun data hasil pengujian dapat dilihat pada Gambar 8.

Berdasarkan Gambar 8, terlihat sinyal kecepatan motor pada saat diberikan beban sebesar 300 gr, diperoleh nilai rise time sebesar $11.50 \mathrm{~ns}$ dan nilai overshoot $44.24 \%$. Nilai rise time sendiri merupakan waktu yang dibutuhkan motor untuk mencapai keadaan steady state time (motor beputar dengan stabil) sedangkan overshoot merupakan nilai dimana ketika kecepatan motor melebihi atau berada di atas nilai setpoint yang ditentukan. Pada saat motor berikan beban, kecepatan motor yang awalnya berada di bawah nilai setpoint, secara perlahan mulai meningkat menuju kecepatan setpoint walaupun motor dalam keadaan berbeban. Ini menunjukkan bahwa pengendali mulai bekerja dalam menjaga kestabilan kecepatan motor ketika diberikan beban.

\section{PENUTUP}

1. Motor induksi 1 fasa tanpa beban memiliki nilai rise time yang semakin kecil ketika kecepatan referensi (kecepatan setpoint) semakin kecil dengan nilai overshoot yang meningkat seiring dengan besarnya nilai kecepatan referensi yang diberikan.

2. Motor induksi 1 fasa pada saat berbeban memiliki nilai rise time yang semakin besar seiring besarnya penambahan beban dengan nilai overshoot yang semakin menurun.

3. Karakteristik Motor Induksi 1 fasa pada saat berbeban memiliki nilai steady state time yang lebih besar untuk beban yang semakin besar dikarenakan pengendali membutuhkan waktu yang lebih lama untuk mengatur motor kembali ke nilai kecepatan setpoint.

4. Pada penerapannya duty cycle bekerja untuk menaikkan kecepatan motor induksi dengan memberikan nilai magnitude tegangan yang tepat sehingga kecepatan motor akan kembali menuju nilai setpoint walaupun terjadi pembebanan.

\section{REFERENSI}

[1].Hidayat, Rahmat. 2013. Pengaturan Kecepatan Putaran Motor Induksi IPhasa Berbasis Mikrokontroller ATMEGA 8535.Universitas Pakuan Bogor.

[2]. Erwanda, Rejani. 2016. Rancang Bangun Prototipe Pengendali Kecepatan Motor Induksi 3 Fasa dengan Pengaturan Tegangan Berbasis Mikrokontroller Arduino dan Android Smartphone. Universitas Lampung.

[3].Wasesa, Tirta. 2014. Perancangan Pengaturan Kecepatan Motor Induksi Satu Fasa dengan PWM Menggunakan Pengendali PID Berbasis Arduino. Universitas Bengkulu

[4]. R, Revlisia. 2012. Metode Pengeringan. Institut Pertanian Bogor.

[5]. Sasmita, Nur R. 2016.Pengeringan Lembaran Karet (Sheet) Dengan Cara Penjemuran, Pengeringan Rumah Kaca dan Pengasapan. Bandar Lampung: Universitas Lampung.

[6].Adawiyah, Dewi Rubaeatul. 2007.Uji Performasi Alat Pengering Efek Rumah Kaca Tipe Rak Dengan Pemanas Tambahan Pada Pengeringan Kerupuk Uyel. Bogor: Institut Pertanian Bogor.

[7].Ogata, Katsuhito. 1997.Modern Control Engineering. London: Prentice-Hall International.

[8].Carr, Joseph. 2011. Practical Antenna Handbook. McGraw-hill Companies.

[9].Sumanto. 1994.Mesin Arus Searah. Andi Offset. Yogjakarta

[10]. Vermis, Nidhi. 2015. Implementation of Solid State Relays For Power Sistem Protection. International Journal of Scientific And Technology Research.

[11]. Spivakovsky, Dyachkov, V. 1978.Conveyor and Related Equipment, Moscow.

[12] McGuire, Patrick M. 1962. Conveyor: Aplication, Selection and Integration, London.. 